\title{
Speed Reading as a Psychological Problem
}

\author{
Angelina Bilaya ${ }^{1, *}$ \\ ${ }^{1}$ Don State Technical University, Ploshchad' Gagarina, 1, 344002 Rostov-on-Don, Russia
}

\begin{abstract}
The demand for innovative learning methods is dictated not only by the speed of changes and updates of the knowledge system, but also by the enormous growth of data. The need to navigate the vast and dynamically changing field of information requires more sophisticated skills of working with it. Reading is still one of the main ways of gaining knowledge. Improving the reading skill allows not only to work with text information faster and more efficiently, but also to qualitatively change the intellectual abilities of a person by means of speed reading. This study presents a theoretical overview of the modern scientific understanding of speed reading, and examines the psychological aspects (cognitive, motivational-meaning-building) that have an impact on the effectiveness of speed reading learning process. Our aim is to develop an appropriate training program, which will take into account not only the capabilities and limitations of the visual and cognitive systems, but also motivationalmeaning-building component, which largely determines the student's involvement in the lesson and the level of results achieved. The implementation of this program in the educational process will allow to optimize the time and effort necessary to acquire a certain amount of educational knowledge, as well as to increase the motivation and personal interest of the individual in the process of education and self-education.
\end{abstract}

\section{Introduction}

\subsection{Research relevance}

In the era of the rapid development of digital technologies and a huge increase in the amount of data, a person faces the problem of information overload and the inability to qualitatively process even a small part of the total amount of data. The current situation challenges traditional reading skills and demands from an individual more advanced, fast and effective forms of working with text information.

The answer to this challenge could be speed reading as an evolutionary form of reading that makes it possible to read a larger number of printed characters per a unit of time with high quality of its comprehension, memorisation and assimilation of the information. Another important aspect of high-quality reading should be the analytical component, which will allow to evaluate the text for consistency, reliability, and compliance of the content of the text with the stated theses.

\footnotetext{
${ }^{*}$ Corresponding author: angelinka k@inbox.ru
} 
Reading is a complex psycho-physiological process, which is studied by many scientific disciplines - psychology, pedagogy, neuropsychology, neurophysiology, etc. However, in science the psychological mechanisms underlying the skill of rapid reading - speed reading - have not been investigated yet. There have not been revealed the components of cognitive abilities, the necessary level of their development. However, these components alongside with the individual motivational-meaning-building characteristics determine a person's ability to successfully master the reading competence.

Traditionally, the reading process is divided into two main components: technical and semantic. Speed reading is a form of reading that combines the high speed of functioning of the two main components. The technical component means the ability to recode printed characters (graphemes) into sounds (phonemes), merge letters into syllables, syllables into words and sentences. The semantic component includes the ability to understand the meaning of words and their combinations in accordance with the context, to identify the levels and spectrum of meanings implied by the author, to be able to generate own meanings as a result of the interaction with the text.

The objective of this study is to identify the psychological and cognitive factors that contribute to the successful formation of these two components, as well as to search for the forms of learning that take into account the motivational component of an individual and the appropriate intensity of learning.

\subsection{Modern Studies of Speed Reading}

The term speed reading, which appeared at the end of the 19th century, has been discredited due to the loud statements made by numerous authors of practical courses about the ability of a person to read at an incredible speed - from 4200-30000 words per minute. Large-scale multi-year study of K. Rayner, Elizabeth R. Schotter, Michael E. J. Masson, Marry C. Potter, Rebecca Treiman [1] refutes such statements and refers to the limitations of human capabilities not so much in the technical part of reading - the ability to see a large number of words per a unit of time, but in its cognitive part. For instance, in the ability to instantly identify a word and its meaning in the presented context, to track its meaning. The findings of the study indicate that it is possible for a reader to improve the speed of reading without losing the quality of comprehension. But to achieve this goal, the reader needs training not in expanding the field of vision or suppressing internal vocalization, but in increasing language competence, enlarging the vocabulary. Thus, it is assumed that advanced (experienced) readers can possibly read at a speed of 250-400 words per minute (for English-language texts) without any loss of comprehension.

In Russia, the upper reading speed limit for school students is 120 words per minute for the 4th grade students (Federal State Education Standard of Primary General Education). In the higher grades, the reading speed parameters are not taken into account, the features that are taken into account are fluency and expressiveness. The school curriculum does not suggest any work on improving the skill of reading fast.

Despite the denial of the possibility of dramatically increasing the reading speed to several thousand words per minute, recent studies conducted by foreign researchers have shown a significant effectiveness of training programs aiming to increase the speed of reading and the level of text comprehension. The data from the study by Sri Wardani are given in Table 1[2].

As a result of 12 -week training of $2 * 45$ minutes per week, including 2 cycles -6 sessions in the first cycle and 4 in the second, Indonesian students demonstrated on average a two-times increase in reading speed and an increase in reading comprehension by almost $10 \%$. 
Table 1. The students` reading fluency in implemented speed reading and extensive reading activities

\begin{tabular}{|l|l|l|l|}
\hline Average score & Preliminary & Cycle 1 & Cycle 2 \\
\hline Reading rate & $112.61 \mathrm{wpm}$ & $224.53 \mathrm{wpm}$ & $268.74 \mathrm{wpm}$ \\
\hline $\begin{array}{l}\text { Reading } \\
\text { comprehension }\end{array}$ & 73.83 & 81.19 & 82.06 \\
\hline
\end{tabular}

Similar results were shown in the study by Abeer Alarfaj and Yousif Alshumaimeri, these data are presented in Table 2 [3]. Students of the University of Saudi Arabia, who took part in a one-year training programme, aimed to increase the speed of reading and reading comprehension demonstrated a significant change in the measured parameters.

Table 2. Values of the test results for the differences in the pre and post test performance in the experimental group

\begin{tabular}{|l|l|l|l|l|l|}
\hline Application & $\begin{array}{l}\text { Arithmetic } \\
\text { average }\end{array}$ & $\begin{array}{l}\text { Standard } \\
\text { deviation }\end{array}$ & T value & $\begin{array}{l}\text { Significance } \\
\text { level }\end{array}$ & $\eta^{2}$ \\
\hline Pre & 149,76 & 38,25 & \multirow{2}{*}{7,47} & $0.000^{*}$ & 0.80 \\
\hline Post & 257,24 & 53,67 & & 0.80 \\
\hline
\end{tabular}

Mahmoud Sulaiman Hamad Bedi Abdelrahman and Muwafaq Saleem Bsharah [4] studied the impact of speed reading strategies on the development of reading comprehension. The experimental group consisted of students of the University in Jordan, the training was held for one academic year. The results demonstrated the effectiveness of using speed reading strategies to improve reading comprehension. The data are presented in Table 3 [4].

Table 3. The results of group in the post-test

\begin{tabular}{|l|l|l|l|l|l|}
\hline Group & $\begin{array}{l}\text { No. of } \\
\text { students }\end{array}$ & Mean & SD & T.TEST & F \\
\hline Experemental & 21 & 87.72 & 1.76 & 13.41 & 0.14 \\
\hline Controlled & 21 & 72.32 & 2.35 & & \\
\hline
\end{tabular}

The influence of reading strategies and speed reading on the development of reading comprehension was also discussed in the work by Amril Amir [5]. The author considered the mutual influence of three variables: reading strategies, speed reading and text comprehension. The findings of the study revealed the regularity of the positive impact of the use of reading strategies on increasing the reading comprehension level $-24.2 \%$. The increase of text comprehension due to the use of speed reading strategy was $33.1 \%$. The combined effect of using reading strategies and speed reading strategies increased the level of text comprehension by $33.2 \%$.

Thus, it can be concluded that the purposeful development of reading skills leads to significant changes in both quantitative and qualitative characteristics of the reader. Let us examine in more detail the capabilities of the visual system and the cognitive skills that affect the ability to master the speed reading skill.

\section{Results}

\subsection{Studies of the capabilities of the visual system in the context of speed reading}


In order to correctly use the techniques and exercises aimed at developing the technical side of reading, it is essential to understand the capabilities and limitations of the visual system.

One of the loud statements made by some authors of speed reading courses sounds like a possibility to expand the vision field to perceive an entire page of text in one fixation.

It is well known that the reading of printed characters occurs by sequentially fixing the gaze on the line - from letter to letter, from word to word.

The acuity of perceiving a visual stimulus by the visual system is highest in the central part of the retina, namely in the area called the fovea. Outside this area - in the parafovea zone (1-5 degrees from the center), the image clarity decreases. In the area of peripheral vision (more than 5 degrees from the central point of fixation), the image is already very blurry, hese data are presented in fig. 1 [6].

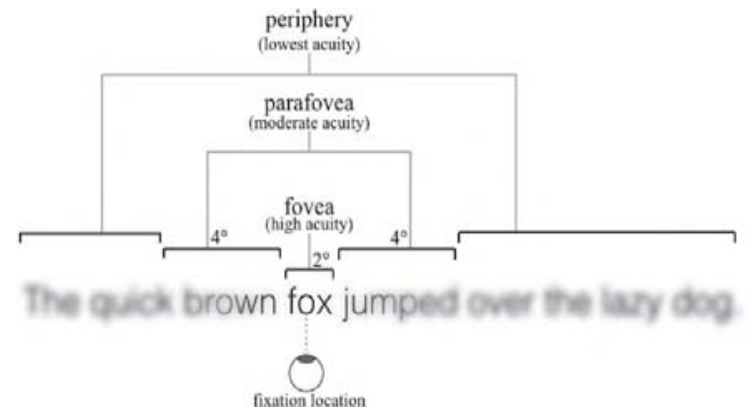

Fig. 1. Diagram illustrating visual acuity across the three regions of the visual field. Acuity decreases continuously as a function of distance from fixation location. The visual field consists of the fovea (center, with highest acuity), parafovea (middle region, with moderate acuity), and periphery (farthest region from fixation, with lowest acuity).

This is due to the peculiarity of the nerve receptors of the eye, which are responsible for visual perception. In the human eye, there are light-sensitive cells called rods and cones. Rods have a high light sensitivity. Cones are sensitive to colors and details, but less sensitive to light. These cones are concentrated in the central region of the retina - the fovea zone, which is the area of best vision. Towards the periphery of the retina, the number of cones decreases, and the number of rods increases. Since the maximum number of detailsensitive cones is located in the central region of the retina, the area of clear vision is limited to this space. It corresponds to the width of the thumb visible at arm's length [1, p. 7].

Therefore, the statement about the ability to clearly perceive large areas of text, equal to a page or even a paragraph, seems to contradict the physiological capabilities of the human visual system.

However, certain training exercises can increase the ability of the peripheral vision area to predict the letters following the fixation area.

The study carried out by Jean-Baptiste Bernard, Amit Arunkumar, Susana T.L. Chung [7] showed that training the peripheral vision area by presenting reading-specific stimuli trigrams - outside the field of clear vision allows to increase the speed of reading by training the skill to predict the written letters according to the general contours. Such training in the field of perception of visual information can be an additional help in mastering the skill of speed reading.

Thus, the increase in reading speed directly depends on the speed and accuracy of the recognition of visual stimuli - letters (at the initial stage of learning to read) and whole words (for more experienced readers). 
The influence of word recognition accuracy on reading speed is also discussed in the paper by Panagiotis Karageorgos, Tobias Richter, Maj-Britt Haffmans, Julia Schindler, and Johannes Naumann [8]. In their longitudinal study, the correlation between the accuracy of word recognition and the reading speed/level of comprehension of texts by primary school students (grades 1-4) was analysed. It was estimated that the faster a student achieves word recognition accuracy ( $71 \%$ or more), the higher are the reading speed and the level of reading comprehension. The authors hope that the early detection of difficulties in forming the accuracy of word perception can signal the difficulties in mastering the reading skill later and will allow to choose a method of correction, which will compensate for these deficiencies at an early stage.

Given that the process of visual perception of the text is carried out through successive fixations and saccades - rapid eye movements from one point of fixation to another, it is necessary to understand what determines the duration of each fixation and the length of the saccades.

According to the "E-Z reader model" [9] and the SWIFT model [10], word identification is primarily determined by when and where the reader decides to change the point of fixation. In our brain there is no pre-set and pre-determined program that supports a certain length of saccades. We adjust these segments in the movement of the eyes in accordance with the constant cognitive processes: understanding of how well we have processed the information coming through the visual analyzer. Thus, the main thing is not the ability to see a certain number of characters, but the ability to recognize a certain value in their combination and give the eyes a signal to move on. It is the cognitive system, not the visual system, which is responsible for successful identifying the meanings of words. In particular, it is the level of the development of language skills.

Thus, setting the task to increase the speed of reading and the level of text comprehension, we must pay close attention to the cognitive mechanisms underlying the identification of the meanings of words and their combinations, in the process of synthesizing them into integral meaningful elements.

\subsection{The study of cognitive abilities in the context of speed reading}

It is necessary to consider those functions of intellect and the level of their development, which, ultimately, will have an impact on the success of mastering speed reading.

One of the first factors mentioned above is the ability to synthesize visual information into enlarged elements. At this stage, reading moves from letter-by-letter reading to reading the whole words and phrases. Good training of the visual system and high reading competence allow to predict the letters in long words and subsequent words in sentences. Here, the function of element-by-element perception is replaced by the function of checking the correctness of the initial assumption: whether the word is predicted correctly or not.

In order to do this, it is necessary to have a large vocabulary and high literacy, to understand the structure and patterns of the language in which the text is read. Thus, those individuals read well who have trained this skill due to large reading experience.

The question raised in this paper is as follows: what can contribute to the development of such a skill in people who do not yet have sufficient experience and training? In other words, the purposeful development of which cognitive skills can lead to similar results in a shorter period of time.

It is also important for us how efficiently the processing of incoming information is carried out, what meanings will be extracted from the text.

Reading is a tool for gaining knowledge, the ultimate goal of which is to supplement, enrich, and restructure a person's mind and experience. For such qualitative changes in the intellect, a person must be able to interact with text information not only at the reproductive 
level - when he or she can retell the content of the text using the author's wording, but also at the reflexive level. Reflexive competence presupposes the ability of the reader to reveal the meanings implied by the author and, as a result of the interaction with the text, generate the reader's own meanings, changing both the content and the structure of consciousness.

Let's put the question this way: what cognitive changes are responsible for the transition to a qualitatively new level of reading?

It is obvious that for reading at a high speed, the quality of information perception must change: it becomes more integrated, the images - more complicated. Speed reading requires not a consecutive, but a simultaneous perception of large meaningful units of the text.

Such view on mind and intellect is presented within the framework of the Gestalt psychological theory, according to which the focus of perception is not individual elements of consciousness, but a phenomenal field of consciousness and a sudden grasp of the relationships between the elements of a problem situation that are important for its resolution - insights [11].

The background for this approach was laid by the works of Kohler [12], and afterwards these ideas were developed by M. Wertheimer in the concept of "productive thinking", in which the leading role is played by the processes of structuring the content of consciousness, grouping, centering, and reorganizing the existing impressions [13].

K. Duncker described the solution of intellectual problems from the point of view of how the content of a person's consciousness changes in the process of finding the principle (idea) of the solution. According to K. Duncker, the key characteristic of intellect is insight - a sudden, instant, unexpected understanding of the essence of the problem. And the more the response is determined by the essential features of the problem situation, the more intelligent it is. That is, intellectually gifted people, according to K. Duncker, are those who find it easier to restructure the mental material [14].

M.Glaser, on the other hand, determined the differences in intellectual abilities according to the degree of the organization of the knowledge system: declarative (what a person knows) and procedural (how a person knows). These peculiarities of the individual knowledge base are responsible for the effectiveness of the cognitive processes (memorization, problem solving), and for the level of intellectual achievements in the profession $[15,16]$.

That is, the existent knowledge, its composition and structure, determine the success of further training. [17]. Thus, the acquisition of knowledge and the way of organizing this knowledge contributes to the development of intellect and intellectual abilities.

Teaching speed reading presupposes a person's interaction with large amounts of text information. On the basis of effective assimilation of the text, an individual can significantly expand the amount of declarative knowledge, which corresponds to the stage of reproductive competence in the assimilation of the material. Comprehensive training should be supplemented by methods of developing thinking within the framework of procedural knowledge: the ability to analyze, synthesize, group and restructure the information received. With this approach, the reader moves to a qualitatively different level, not only in the ability to perceive information, but also in the ability to adequately structure it in the meaning-building and conscious field.

\subsection{Motivational factor in teaching speed reading}

The success of any training depends on the degree of a student's involvement and interest in the educational process, on the desire to achieve certain results, as well as on the degree of compliance of their own interests with the subject of study. 
A large selection of educational, fictional and scientific literature, its styles and formats of presentation makes it possible to organize the process of teaching speed reading in accordance with the diversity of students' interests.

Intellectual abilities are characterized by peculiarities of the individual knowledge base. The fact of the matter is that "in order to explain intellectual productivity, not the amount of the acquired knowledge, but the ways in which it is stored and reproduced in an individual knowledge base are important" [11].

An individual's choice of a particular subject area of interest, in which he or she wants to be an expert and professional, implies the creation of an appropriate knowledge base, in which, through the construction of semantic networks and the structure of semantic data, the individual builds his or her own ideas about what is going on, as well as creates rules (procedures) by which he or she will use this knowledge. The level of the organization of this database will be indicated by the easy availability of this knowledge and its suitability for use.

Therefore, a student should not have the goal of gaining as much miscellaneous knowledge from different spheres as possible. The understanding of the meaninglessness of such a task is expressed both in the saying "multi-knowledge does not teach the mind", and in the estimation of the low value of the "dead weight of unorganized knowledge" by representatives of the knowledge approach in the study of intellect.

Orientation to the sphere of personal interest and independent choice of the area of knowledge arousing interest allows not just to receive miscellaneous information, but to build and reconstruct the image of the situation in the area of interest, turning semantic memory into a "special cognitive process of generalization and organization of acquired knowledge" [11].

Thus, the training should be organized taking into account the individual characteristics of the cognitive and personal-meaning-building components of the personality [18].

\section{Discussion}

As stated in the paper by Panagiotis Karageorgos, Tobias Richter, Maj-Britt Haffmans, Julia Schindler, and Johannes Naumann [8], the speed of mastering the skill of accurate word recognition by primary school students determines both the speed of reading in the future and the level of text comprehension. It is obvious that the ease of working with text information makes a student more successful in both the field of getting educational knowledge and in the field of the acquisition of cultural values.

By increasing the reader's competence and literacy, we provide the opportunity for faster and more productive learning at all levels and in all areas: educational, professional, scientific, personal (self-development).

"Thanks to the development of verbal and logical means of intellectual activity, individual experience through the meanings of words and logical reasoning is immersed in the universal experience, which inevitably leads to the qualitative expanding of the intellectual world of an individual" [11].

It can be stated that "in the framework of the above mentioned approach to understanding the competence of speed reading, it can become not only a method of optimizing and improving the efficiency of intellectual work, but also a way to improve and develop a personality in general." [19].

Ideally, the goal of education should be not only the development of the cognitive functions of the individual and the transfer of the system of knowledge and methods of cognition, but also the development of the psychological functions, i.e. the creation of such conditions in which he or she will have an opportunity to realize the unique abilities and values. Understanding the educational process in this way shifts the focus from students' 
mere learning the subjects - literature, mathematics, geography - to the intellectual education of the students by means of literature, mathematics, geography, etc.

Under this approach, we can talk about speed reading as one of the tools of intellectual education and personal development, where the ultimate goal is not only the achievement of a certain reading speed and the ability to assimilate large amounts of text information, but also the ability to use this skill to achieve more global goals by means of speed reading: the development and acquisition of cultural values and meanings, self-understanding, selfdevelopment.

\section{Conclusion}

It is difficult to calculate how many hours it will take a modern person in order to read and assimilate the total of currently existing educational and cultural texts. Despite the fact that audio and video learning formats are becoming increasingly popular, reading is still the main source of gaining knowledge. All educational programs, as well as the cultural heritage of the humanity- poetry, literature - are presented in the text form. Therefore, the reading skill level determines the amount and the quality of the acquired information.

Unlike audio and video formats that exploit involuntary attention, reading requires focused and active participation in the process. Therefore, the level of the development of such cognitive skills as the ability to control the attention, the ability to analyze, synthesize and systematize information, should correspond to the tasks set to the reader.

Speed reading, as a more advanced form of reading, requires a high level of development of both the technical and semantic aspects of reading. The use of methods of purposeful development of this competence leads to the improvement of general and particular cognitive skills, including the skills of perception and processing information.

Obviously, as a more complex and energy-consuming form of acquiring knowledge, reading loses its appeal and value to the younger generation. It is much easier to watch a video or listen to a recorded text than spend a lot of time and effort sitting over books.

However, the possession of a special skill that opens up additional opportunities for the individual can become a significant motivating factor at the beginning of training and an effective learning tool afterwards.

Our task is to develop an appropriate training program that takes into account the described above capabilities and limitations of the visual and cognitive systems. The program should also include a motivational-meaning-building component, which to a great extent determines the student's involvement in the lesson and the level of the results achieved.

The implementation of this program in the educational process will allow to optimize the time and effort necessary to acquire a certain amount of educational knowledge, as well as to increase the motivation and personal interest of the individual in the process of education and self-education.

\section{References}

1. K. Rayner, E.R. Schotter, M.E.J. Masson, M.C. Potter, R. Treiman, So Much to Read, So Little Time: How Do We Read, and Can Speed Reading Help? Psychological Science in the Public Interest, 17(1), 4-34 (2016) doi: https://doi.org/10.1177/1529100615623267

2. S. Wardani, Using speed reading and extensive reading activities to improve students'reading fluency. Journal Pendidikan Humaniora, 2(3), 219-227 (2014) 
3. A. Alarfaj, Y. Alshumaimeri, The effect of a suggested training program on reading speed and comprehension of Saudi female university students. Procedia - Social and behavioral science, 31, 612-628 https://doi.org/10.1016/j.sbspro.2011.12.114

4. M.S.H.B. Abdelrahman, M.S. Bsharah, The effect of speed reading strategies on developing reading comprehension among the 2nd secondary students in English language, English Language Teaching, 7(6), 168-174 (2014) doi: https://doi.org/10.5539/elt.v7n6p168

5. A. Amril, The effect of reading strategies and speed reading on students' reading comprehension skill in higher education. In: Advances in social science, education and humanities research. Proceedings of the Seventh International Conference on Languages and Arts (ICLA 2018), 301, 409-412 (Atlantis Press, 2018)

6. D.A. Bolota, K. Rayner, Word recognition processes in foveal and parafoveal vision: The range of influence of lexical variables, Basic processes in reading: visual word recognition, 198-232 (Erlbaum, Hillsdale, 1991)

7. J.-B. Bernard, A. Arunkumar, S.T.L. Chung, Can reading-specific training stimuli improve the effect of perceptual learning on peripheral reading speed? Vision research 66, 17-25 (2012) doi: https://doi.org/10.1016/j.visres.2012.06.012

8. P. Karageorgos, T. Richter, M.-B. Haffmans, J. Schindler, J. Naumann, The role of word-recognition accuracy in the development of word-recognition speed and reading comprehension in primary school: A longitudinal examination. Cognitive Development 56, 100949 (2020) doi: https://doi.org/10.1016/j.cogdev.2020.100949

9. E.D. Reichle, A. Pollatsek, D.L. Fisher, K. Rayner, Towards a model of eye movement control in reading. Psychological Review, 105, 125-157 (1998)

10. R. Engbert, A. Nuthmann, E.M. Richter, R. Kliegl, SWIFT: A dynamical model of saccade generation during reading. Psychological Review, 112, 777-813 (2005)

11. M.A. Holodnaya, Psychology of intelligence: Paradoxes of research (Piter, St. Petersburg, 2002)

12. S. Sabar, What's a Gestalt? Gestalt Review, 17(1), 6-34 (2013)

13. M.A. Runco, S.R. Pritzker, Max Wertheimer 1880-1943, Encyclopedia of Creativity (Second Edition), 515-520 (Academic Press, 2011) doi: https://doi.org/10.1016/B9780-12-375038-9.00268-5

14. K.A. Duncker, A qualitative (experimental and theoretical) study of productive thinking solving of comprehensible problems. Pedagogical Seminary and Journal of Genetic Psychology, 33, 642-708 (2012)

15. R. Glaser, A research agenda for cognitive psychology and psychometrics. Amer. Psychologist, 36(9), 923-936 (1980)

16. R. Glaser, Education and thinking: the role of knowledge. Amer. Psychologist. 39(2), 93-104 (1984)

17. J. Campion, A. Brown, R. Ferrara, Mental retardation and intelligence. Handbook of human intelligence, 392-490 (Cambridge Univ. Press, Cambridge, 1982)

18. I.V. Abakumova, Meaning didactics: Textbook for Masters of Education and Psychology degree (CREDO, Moscow, 2008)

19. A.M. Bilaya, Speed reading as a tool for personal development. Innovative science: psychology, pedagogy, defectology, 3(2), 32-48 (2020) 